\title{
Systematic design of an atmospheric data acquisition flying vehicle telemetry system
}

\author{
Vahid Bohlouri $^{\mathrm{a}}$, Amir Reza Kosari ${ }^{\mathrm{a}}$ and MRM Aliha ${ }^{\mathbf{b}^{*}}$
}

${ }^{a}$ Faculty of New Science and Technology, University of Tehran, Iran

${ }^{b}$ Welding and Joining Research Center, School of Industrial Engineering, Iran University of Science and Technology (IUST), Narmak, 16846-13114, Tehran, Iran

\begin{tabular}{|c|c|}
\hline $\begin{array}{l}\text { ART I C LE I NFO }\end{array}$ & A B S T R A C T \\
\hline $\begin{array}{l}\text { Article history: } \\
\text { Received March 6, } 2014 \\
\text { Accepted 23 August } 2014 \\
\text { Available online } \\
\text { 24 August } 2014 \\
\text { Keywords: } \\
\text { Flying Vehicle } \\
\text { CanSat } \\
\text { Systematic Design } \\
\text { Telemetry System }\end{array}$ & $\begin{array}{l}\text { In this paper, we have provided hands-on experience in systematic design, implementation and } \\
\text { flight test of an atmospheric data acquisition flying vehicle as a standard CanSat telemetry } \\
\text { mission. This system is designed for launching from a rocket at a separation altitude about } \\
\text { 1000-meter. During its flight, the reusable flying vehicle collects environmental data and } \\
\text { transmits it directly to the ground station. The ground station, which is implemented at a pre- } \\
\text { defined radio frequency band receives data and plots the respective graphs. The design } \\
\text { performs based on a systematic approach, in which the first step is set aside to mission and } \\
\text { objectives definition. In the next step, the system requirements are identified and the required } \\
\text { main subsystems and elements with their technical requirements will be extracted. The structure } \\
\text { analyses were also performed by ABAQUS software to obtain the natural frequency and the } \\
\text { mode shape. The wireless communications, onboard microcontroller programming, sensor } \\
\text { interfacing and analog to digital conversion describe the basic technologies employed in the } \\
\text { system implementation. This flying vehicle in comparison with the other similar ones is more } \\
\text { lightweight, has few interface circuits and high precision sensors. According to the flight test } \\
\text { outputs, low power consumption, high transmit line up to } 2 \text { Km despite of limitation in TX } \\
\text { power and up to } 10 \text { normal acceleration withstanding are important specific characteristics of } \\
\text { the implemented flying system. }\end{array}$ \\
\hline
\end{tabular}

\section{Introduction}

Flying vehicle design and development process involves identification of its requirements, listing of tasks to accomplish and identification and allocation of required resources for its successful execution. Generally, the life cycle of a flying mission progresses through four phases: Design, Production, Operations and Support (Larson \& Wertz, 1992). The main challenge in design procedure of a flying vehicle is its multi-disciplinary nature. This is characterized by degrees of influences that

* Corresponding author.

E-mail addresses: mrm_aliha@iust.ac.ir (M. R. M. Aliha) 
each design discipline has on the others. In this work, a telemetry system of a small satellite is designed, fabricated and tested based on a predefined set of design requirements. CanSat is consisted of two words, Can and Sat, which means a satellite in the size of the standard beverage can and it is called to system used in competitions held all over the world to train the future space engineers and get them to become familiar with aerospace activities (Nylund \& Antonsen, (2007)). There are four phases in response of system requirements, which could be considered as follows:

- Mission Analysis \& Feasibility study

- Preliminary Design

- Critical Design and Construction

- Test \& Modification

The Operational Requirement Document (ORD) is the basis for acquiring of System Requirement Document (SRD). It became the main source for developing system architecture, identification of subsystem requirements and their preliminary design. In the following sections, both system and operation requirement and design of subsystems and implementation of atmospheric data acquisition telemetry system are briefly described and some flight test results are presented and discussed to demonstrate the logical proposed systematic approach (Wittmann \& Hallmann, 2009).

\section{System Design}

According to V chart, system design including system level and the level of detail. In system level, objective, mission, constraint, requirement and tests are discussed. In the following the key required system design demonstrates including, the Mission Needs Statement, Operational Requirement Document, System Technical Requirement, System Architecture, Identification of Requirement are illustrated (Larson \& Wertz, 1992).

\subsection{Mission Needs Statement (MNS)}

In this phase, the design performed based user needs, thus first should define the needs or requests of customers. It is responsibility of designers to translate them to operational needs and document in Mission Needs Statement (MNS). MNS clears that what problem is trying to solve in the program. For this project, the MNS is as follows: The measure of atmospheric data for scientific experiments are needed and requested. The desired system must be designed in soft drink can size and weight. It must be autonomous and send the data of ambient pressure, humidity, temperature, GPS location and acceleration in real time into a ground station. This system can be launch from rocket or balloon. In addition, it must have the safe landing and must be ability of operation for 1 hour (Wasson (2006)).

\subsection{Operational Requirement Document}

MNS must be translated by operator into an Operational Requirement Document (ORD) that is validated by collaboration with the users. ORD is: the system will be a small satellite analog which all of its components must be housed inside a cylinder, $115 \mathrm{~mm}$-height and $66 \mathrm{~mm}$-diameter with maximum weight of 350 grams. Albeit, the deployable subsystems and recovery system can exceed the length of the primary structure, up to a maximum length of $230 \mathrm{~mm}$. System is launched and ejected from a rocket or a balloon. By the use of a parachute, it slowly descends back to earth performing its mission while transmitting telemetry. The telemetry data will include the barometric altitude, ambient humidity and temperature, GPS location and acceleration. This system must be fully autonomous and its data sending must be real time. The system is not allowed to use dangerous materials. The power supply must supply the systems at least 1 hour (Nylund \& Antonsen (2007)). 


\subsection{System Technical Requirement}

Technical requirements will be derived from ORD justification methods of these requirements are listed in Table1.

Table1. The system technical requirement

\begin{tabular}{|c|c|c|}
\hline number & Requirement & Justification Method \\
\hline 1 & Maximum mass is 350 gram & Inspection \\
\hline 2 & Volume is a cylinder with $115 \mathrm{~mm}$-height and $66 \mathrm{~mm}$-diameter & Inspection \\
\hline 3 & Maximum exceed length is $230 \mathrm{~mm}$ & $\begin{array}{l}\text { Inspection Design } \\
\text { Review }\end{array}$ \\
\hline 4 & Maximum speed descent is $5 \mathrm{~m} / \mathrm{s}$ & Test Analysis \\
\hline 5 & Withstand 10 g Acceleration & Test Analysis \\
\hline 6 & 1 hour power & Test Analysis \\
\hline 7 & The system do not use photoelectric sensors. & $\begin{array}{l}\text { Inspection Design } \\
\text { Review }\end{array}$ \\
\hline 8 & Maximum Rocket Altitude 1000 meter & Inspection \\
\hline 9 & $\begin{array}{l}\text { Sending follows Data: Barometric altitude, ambient humidity and } \\
\text { temperature, GPS location and acceleration }\end{array}$ & Design Review \\
\hline 10 & Do not use pyrotechnics, flammable or dangerous material & $\begin{array}{l}\text { Inspection Design } \\
\text { Review }\end{array}$ \\
\hline 11 & The total cost of the system cannot exceed 1000 Euros. & Design Review \\
\hline 12 & System must withstand vibration forces due to rocket launch & Analysis \\
\hline
\end{tabular}

\subsection{System Architecture}

The system architecture was performed based on the operational concept. Thus, this system architecture should be considered the following sections.

- structure and mechanism

- $\quad$ Recovery and Descent control

- $\quad$ Electrical and Electronics

- Communication and ground station

Moreover, the according to the objective, mission and requirements of the subsystems are:

- Electrical Power

- Data Handling

- Communication

- Grand station

- Recovery

- $\quad$ Structure and Mechanism

- Payload

\subsection{Identification of Requirement}

In this step, the technical requirements of all subsystems are derived from mission, operation and system requirements. These requirements which are on the basis of subsystems deign are listed in Table 2 (Eerkens et al., 2008). 
Table 2. Telemetry system requirements

\begin{tabular}{|c|c|c|}
\hline Number & Structure Requirements & Justification Method \\
\hline 1 & The dimensions should be cylinder with $66 \mathrm{~mm}$ (diameter) and $115 \mathrm{~mm}$ (Height). & Inspection \\
\hline 2 & There must be no protrusions until the system release and deployment from the rocket payload. & $\begin{array}{l}\text { Inspection } \\
\text { Design Review }\end{array}$ \\
\hline 3 & No electronic/mechanical control is employed to push the CanSat out of payload. & $\begin{array}{l}\text { Inspection } \\
\text { Design Review }\end{array}$ \\
\hline 4 & CanSat must withstand vibration forces due to rocket launch. & Analysis \\
\hline 5 & The structure shall support electronics during flight and Impact. & Test Analysis \\
\hline 6 & The structure must provide required space for placement of all subsystems excluded parachute. & Design Review \\
\hline \multicolumn{3}{|c|}{ Recovery System Requirements } \\
\hline 1 & The average descent rate of system after deployment shall be lower than $5 \mathrm{~m} / \mathrm{s}$. & Test Analysis \\
\hline 2 & The attachment of the recovery system must withstand $10 \mathrm{G}$ in the moment of its deployment. & Test Analysis \\
\hline 3 & $\begin{array}{l}\text { The parachute and its paraphernalia must be fitted in cylindrical place with maximum dimension of } \\
66 \mathrm{~mm} * 115 \mathrm{~mm} \text { (the allowable parachute space) }\end{array}$ & Inspection \\
\hline 4 & The attachment of recovery system must be fixed directly to the primary structure. & Inspection \\
\hline 5 & The parachute must be fully opened after 8 seconds. & Analysis Test \\
\hline \multicolumn{3}{|c|}{ Data Handling Subsystem Requirements } \\
\hline 1 & $\begin{array}{l}\text { Numbers of components which use UART or SPI as interfaces with microcontroller should be } \\
\text { compatible with number of UART or SPI interfaces in microcontroller. }\end{array}$ & Design Review \\
\hline 2 & The telemetry packets must be transmitted at rate of $1 \mathrm{~Hz}$ & Test \\
\hline 3 & Microcontroller should be able to handle all sensor data. & Test Analysis \\
\hline 4 & Microcontroller should store sensor data on-board memory. & Test Analysis \\
\hline 5 & Data transmission must be terminated after landing detected. & Design Review \\
\hline \multicolumn{3}{|c|}{ Power subsystem Requirements } \\
\hline 1 & $\begin{array}{l}\text { Operating voltage range for battery and regulator must be compatible with sensor \& other electrical } \\
\text { components. }\end{array}$ & $\begin{array}{l}\text { Test Design } \\
\text { Review }\end{array}$ \\
\hline 2 & All components should be supplied with a unique battery. & Inspection \\
\hline 3 & The battery voltage must be higher than 3.3V. & Design Review \\
\hline \multicolumn{3}{|c|}{ Communication Subsystem Requirements } \\
\hline 1 & The configuration of communication subsystem must include the transmitter and receiver. & $\begin{array}{l}\text { Inspection Design } \\
\text { Review }\end{array}$ \\
\hline 2 & Minimum transmitting range of data should be $1000 \mathrm{~m}$. & Analysis Test \\
\hline 3 & Maximum emission power must be equal or lower than the allowable level of 2 to $5 \mathrm{Watt}$ & $\begin{array}{l}\text { Analysis Design } \\
\text { Review }\end{array}$ \\
\hline 4 & The range of frequency is between $2-2.4 \mathrm{GHz}$ & $\begin{array}{l}\text { Analysis Design } \\
\text { Review }\end{array}$ \\
\hline 5 & Coding of Data & Analysis Test \\
\hline \multicolumn{3}{|c|}{ Payload Subsystem Requirements } \\
\hline 1 & Humidity sensor must have a range of at least $20 \%$ to $90 \%$ (Worst case). & $\begin{array}{l}\text { Test Design } \\
\text { Review }\end{array}$ \\
\hline 2 & Pressure sensor must have a range of at least $60 \mathrm{kPa}$ to $90 \mathrm{kPa}$. & $\begin{array}{l}\text { Test Design } \\
\text { Review }\end{array}$ \\
\hline 3 & Temperature sensor must have a range of at least $-10^{\circ} \mathrm{C}$ to $+50^{\circ} \mathrm{C}$. & $\begin{array}{l}\text { Test Design } \\
\text { Review }\end{array}$ \\
\hline \multicolumn{3}{|c|}{ Ground Station Requirements } \\
\hline 1 & Connect with transponder & Test Design Review \\
\hline 2 & Receive, Amplify and plot data & Test Design Review \\
\hline 3 & Decoding of Data & Test Design Review \\
\hline
\end{tabular}

\section{Subsystem Design}

In detail level, the subsystems and elements are discussed and designed. Designing phase, leads to preliminary and critical designs, fabrication phase which consists of simulations, part procurement, testing electronic devices, subsystem fabrication and test and system assembly. The last phase 
includes the final operational tests and evaluations. In the next section we illustrate the detail of a satellite namely subsystems and elements based on Larson and Wertz (1992).

\subsection{Electrical Power Subsystem}

The electrical power subsystem should provide adequate power for at least one hour. A pack of three lithium polymer battery cells of $3.7 \mathrm{~V}$ and $1000 \mathrm{~mA}$.h, along with 2 regulator ICs have been employed to provide the required power and voltages on a bus connected to each subsystem. To avoid the voltage drops, caused by consuming too much power by high power consuming parts, some extra precautions have been considered. These precautions include separating the high power consuming part from other parts and using some capacitor filters to avoid noise. The power subsystem structure is presented in figure 1 that power subsystem consists of 3 parts, battery, regulator and filter. The results showed that this pack could provide the system with sufficient and reliable power for more than one hour.

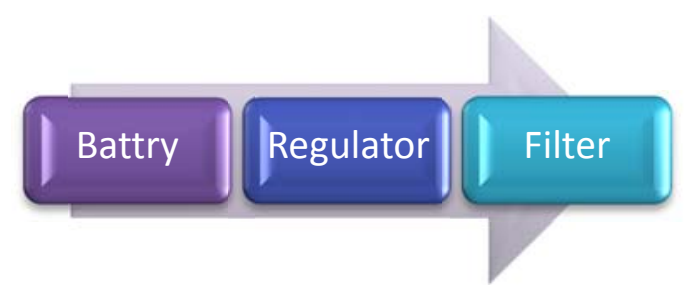

Fig.1. Power subsystem structure

\subsection{Communication subsystem}

The communication subsystem should send online data, collected by telemetry system, and receiving the sent data in the ground station. Here, the RF power, frequency range, transmission rate and the distance between the transmitter and receiver should be taken into considerations. The allowed frequency band in Iran is about $2.4 \mathrm{GHz}$ at maximum RF power of 1 watt. Here the test showed that a $2.4 \mathrm{GHz}$ module, using $5 \mathrm{db}$ antennas, in transmitter and receiver modules, with 100 milli Watt RF power can be used to transmit data to a receiver, placed as far as of $2 \mathrm{Km}$ in line of sight. For security issues, the data is coded then transmitted to a predefined receiver node. The received data is plotted in MATLAB software after decoding. ZigBees are communication module. A ZigBee module is used for data transmission. Communication subsystem has the following specifications:

- Frequency range used for data transmission/reception is 2400-2500 $\mathrm{MHz}$ which supports maximum range of 2000 meter.

- Data Coding

- Maximum RF power: 1 watt

- Maximum emission level: 100 milli Watt

- Maximum bandwidth (5dB): 5 MHZ

For using the ZigBee module the transmitter follows the IEEE 802.15.4-compliant coprocessor (Moghaddam et al. (2013)).

\subsection{Data Handling Subsystem}

The data handling subsystem has been used to manage of connection between different subsystems, collect data and send it to the communication subsystem. This subsystem consists of the microcontroller and SD card used to save data. An 18f series PIC microcontroller has been used due 
to its reliability. Different protocols such as $\mathrm{I}^{2} \mathrm{C}$, serial and SPI have been used to collect data form sensors and save them into the SD memory card. Due to the limited space, weight and electrical power allocated to this system, the used sensors are chosen with sufficient sensitivity and reliability, such that the consumed power and space would be minimal. To facilitate the connections of the sensors to the MCU and to avoid the extra complications in circuit designing, most sensors have been selected as digital sensors. The final PCB board has been depicted in Fig. 2 (PIC18FXX2 Data Sheet).

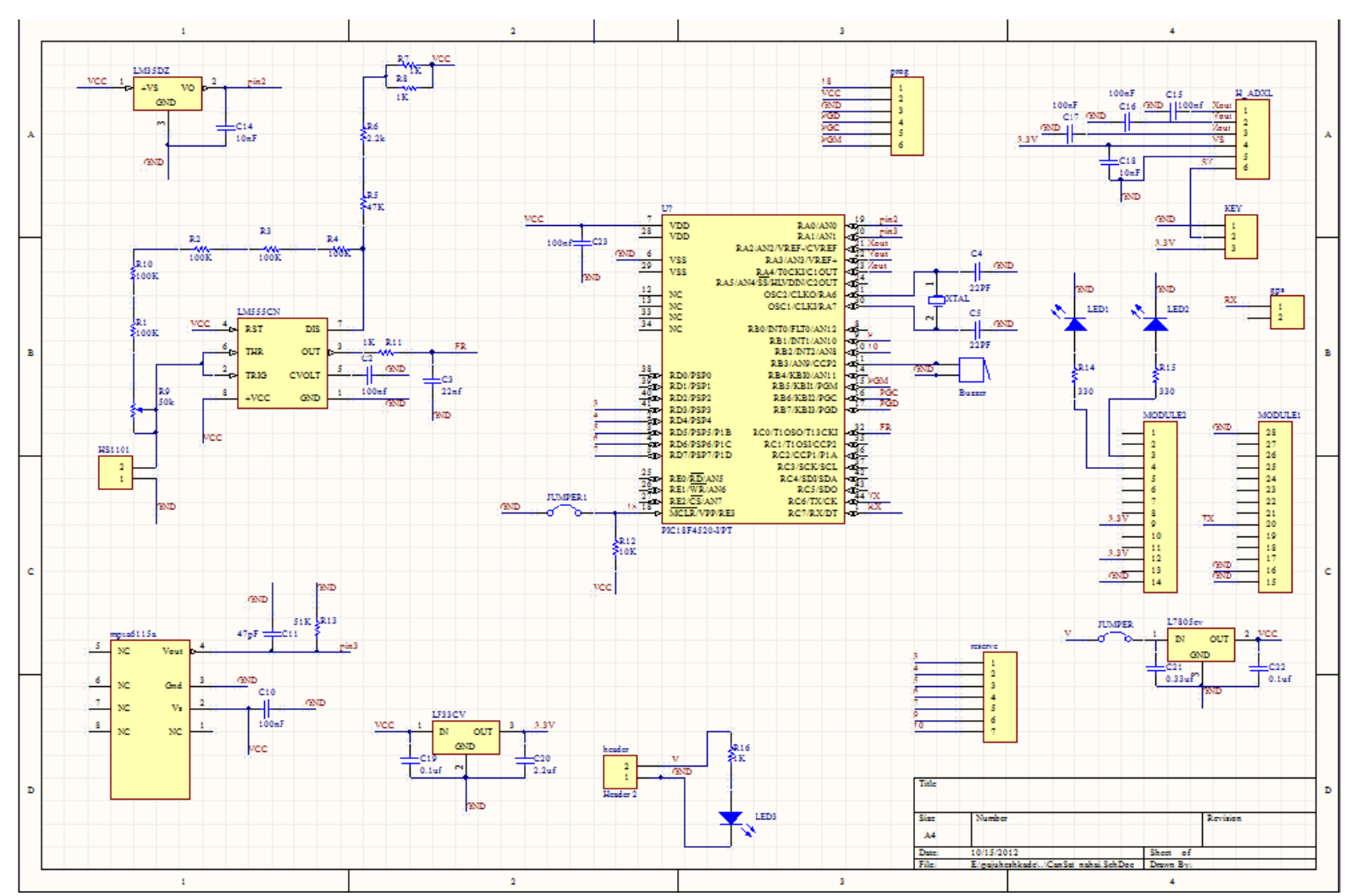

Fig. 2. PCB board and electronic simulation

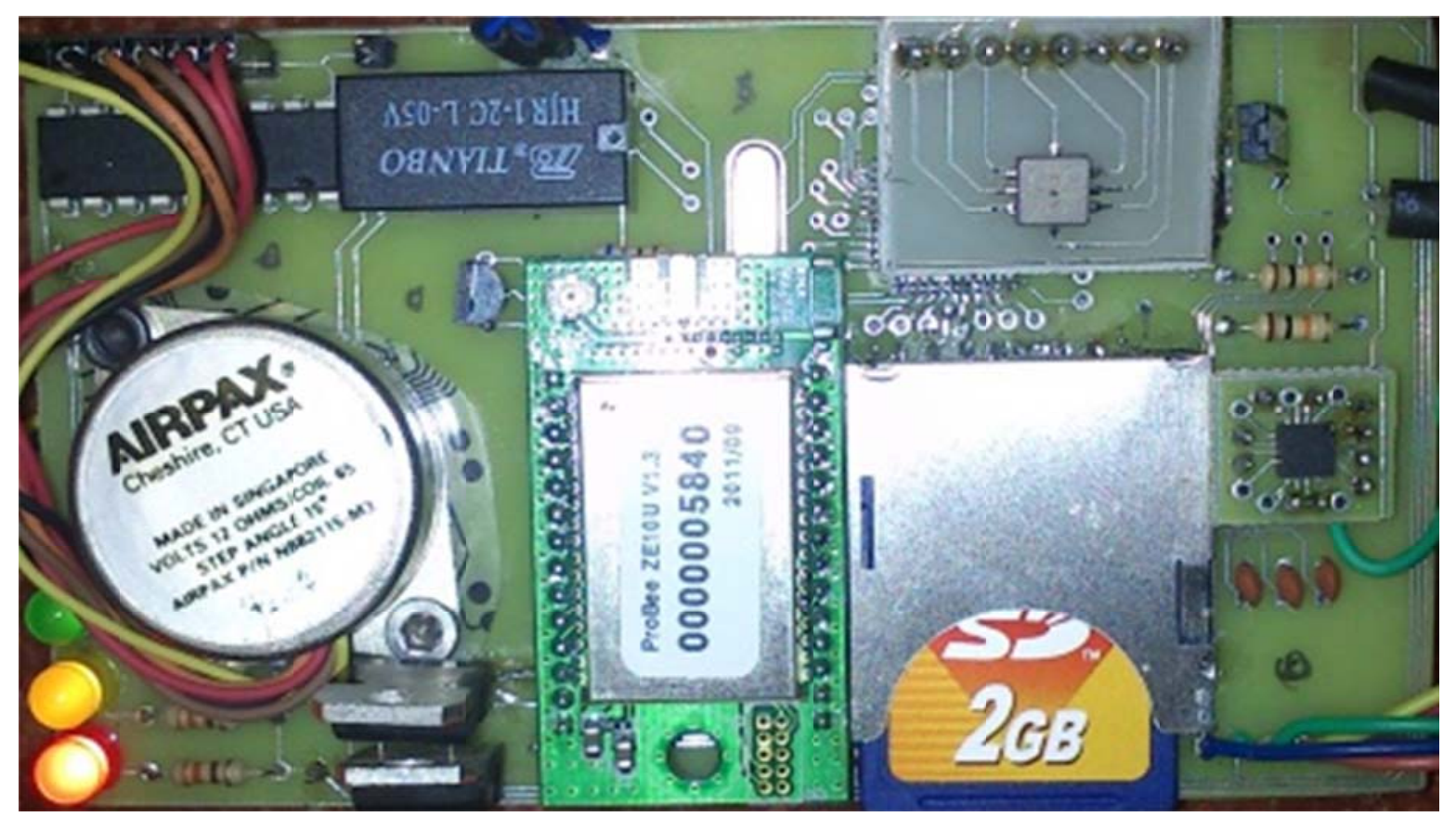

Fig. 3. Main board consists of processor, communication, payload and stepper motor. 


\subsection{Payload}

The payload subsystem is required to accomplish the objective of the mission. Here the payload consists of temperature, humidity, pressure, acceleration and GPS sensors. These parameters have been collected and transmitted to the data handling subsystem. Due to the small size and low power consumption of MEMS sensors, pressure and acceleration sensors are chosen to be MEMS sensors. The required sensors are temperature, humidity, pressure, acceleration, GPS and sensors. The integrated board of payload, data handling, stepper motor and communication subsystems has been shown in Fig. 3. The electrical power consuming in electronic section illustrated in Table3.

\subsection{Structure and Mechanism subsystem}

Structure design was done by consideration of following points as well as dedicated requirements:

- Having a total mass of no more than 350 grams, forces that the structure must be light-weight while having enough strength and durability.

- It must be easy to disassemble.

- To have an efficient use of the hardware such as GPS and sensors, they need to be positioned at the best place.

- The center of mass of the structure must be as low as possible to create a stable equilibrium of the telemetry system. In fact, when the center of mass is placed under the center of volume, the system tends to stay at the vertical direction.

Table 3. Power consumption

\begin{tabular}{cccc}
\hline Component Name & Current & Operating Voltage (v) & Power \\
\hline Temperature sensor & $10 \mathrm{~mA}$ & 5 & $50 \mathrm{mw}$ \\
Humidity sensor & $500 \mu \mathrm{A}$ & 5 & $2.5 \mathrm{mw}$ \\
Pressure sensor & $100 \mu \mathrm{A}$ & 5 & $0.5 \mathrm{mw}$ \\
Accelerometer & $180 \mu \mathrm{A} \sim 375 \mu \mathrm{A}$ & 3.3 & $594 \mu \mathrm{w} \sim 1.237 \mathrm{mw}$ \\
PIC microcontroller & $2 \mathrm{~mA} \sim 25 \mathrm{~mA}$ & 5 & $10 \mathrm{mw} \sim 125 \mathrm{mw}$ \\
Transmitter & $190 \mathrm{~mA}$ & 3.3 & $627 \mathrm{mw}$ \\
GPS & $80 \mathrm{~mA}$ & 3.3 & $264 \mathrm{~mW}$ \\
\hline Total & Typical: $202.78 \mathrm{~mA}$ & - & Typical: $690.594 \mathrm{mw}$ \\
& Worst case: $225.975 \mathrm{~mA}$ & Worst case: $806.237 \mathrm{mw}$ \\
\hline
\end{tabular}

The structure should be used to cover and protect other subsystems and its size should not be bigger than a standard beverage can. Fiberglass was used as the structural material, due to its lightweight and high strength. The structure can withstand the acceleration as big as $10 \mathrm{~g}$. To accomplish extra missions, some mechanisms have been used as an actuator to extend the antenna. In order to satisfy the natural frequencies and mode shape requirements of the cansat a modal analysis was performed using ABAQUS software. The computed natural frequencies are listed in Table 4 and the first six mode shapes of structure are shown in Fig. 4. The obtained natural frequencies that are quite higher than the natural frequency of the rocket, demonstrate that the resonance will not occur during the lunch. Fig. 5 also shows the overall displacements of structure under the force applied by the acceleration of $10 \mathrm{~g}$. Based on this figure the displacement induced by this acceleration is very small and hence the structure can withstand the loads safely.

Table 4. Natural Frequency

\begin{tabular}{cc}
\hline Mode & Frequency $(\mathrm{Hz})$ \\
\hline Mode1 & 190.3 \\
Mode2 & 264.8 \\
Mode3 & 391.14 \\
Mode4 & 393.71 \\
Mode5 & 396.25 \\
Mode6 & 420.19 \\
\hline
\end{tabular}



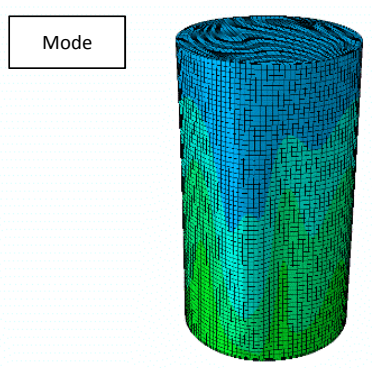

Mode4

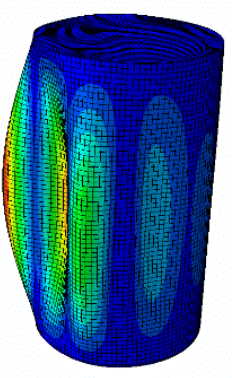

Fig.4. The first 6 shape modes of cansat structure

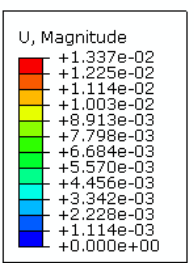

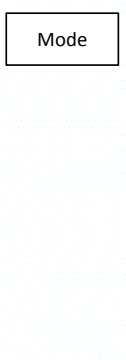
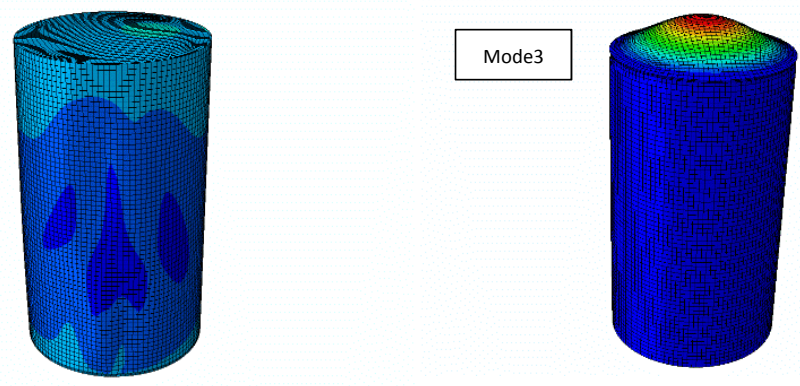

Mode5

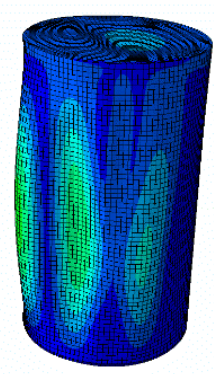

Mode6

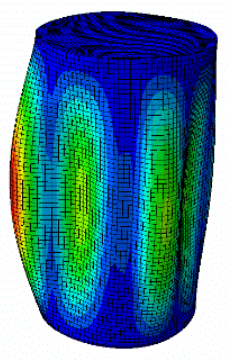

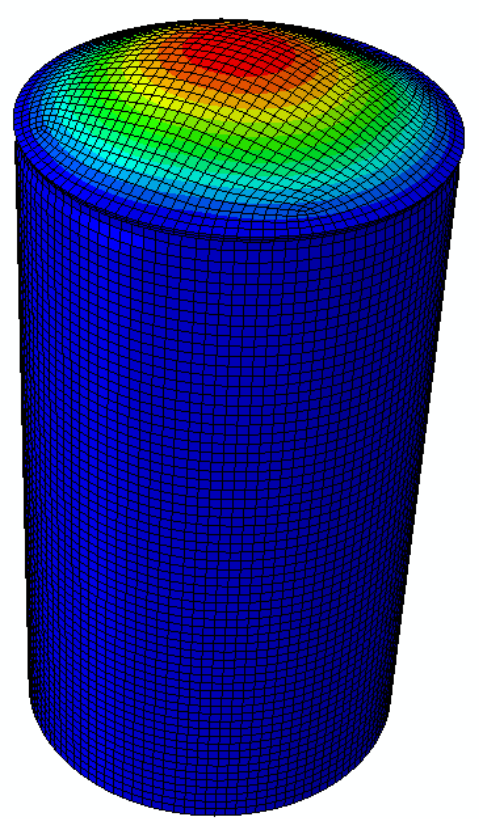

Fig.5. Deformation of cansat structure under $10 \mathrm{~g}$ acceleration

\subsection{Mass Budget}

The mass is a one of the most important items and thus this parameter must manage and budget. Table 5 illustrates the system mass budget. The other important budgets have been presented also in Fig. 6 for the investigated CanSat. 
Table 5. System Mass Budget

\begin{tabular}{clcc}
\hline & Component & Reference & Mass (gram) \\
\hline 1 & Structure & Homemadle & 40 \\
2 & Recovery Subsystem & Homemadle & 60 \\
3 & Data Handling + Payload + Power Subsystem & & 153 \\
& $-\quad$ Temperature sensor & LM35 & 2 \\
& $-\quad$ Humidity sensor & Hs1101 & 3 \\
& $-\quad$ Pressure sensor & MPXAZ6115A & 3 \\
& $-\quad$ Accelerometer sensor & ADX330L & 10 \\
& (by considering PCB Board) & GT723F & 5 \\
& $-\quad$ GPS & Li-ion 2200 mA & 70 \\
& $-\quad$ Battery & PIC18F877 & 60 \\
& $-\quad$ Microcontroller & ZigBee-ZE10 & 15 \\
& (by considering PCB Board) & & 5 \\
& Communication Subsystem & & 10 \\
\hline 6 & $-\quad$ XB-Pro & & 268 \\
\hline Total & $-\quad$ Antenna & &
\end{tabular}
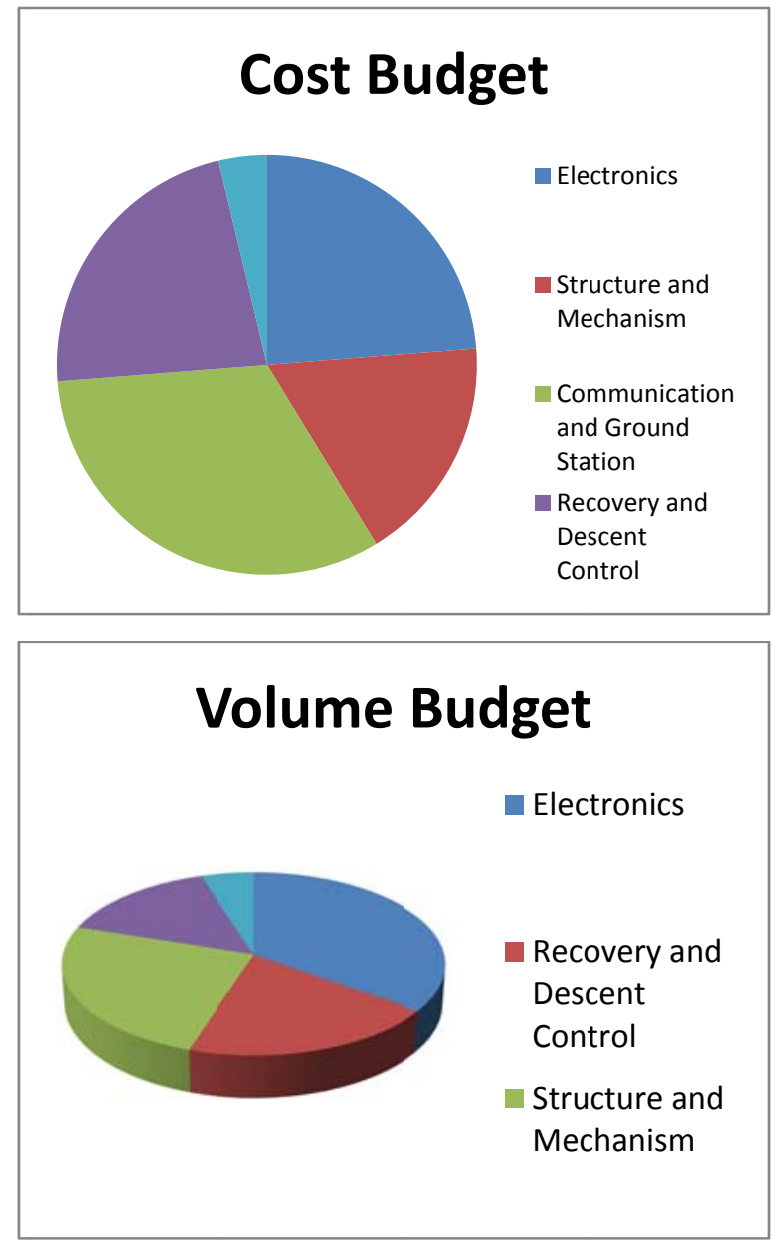
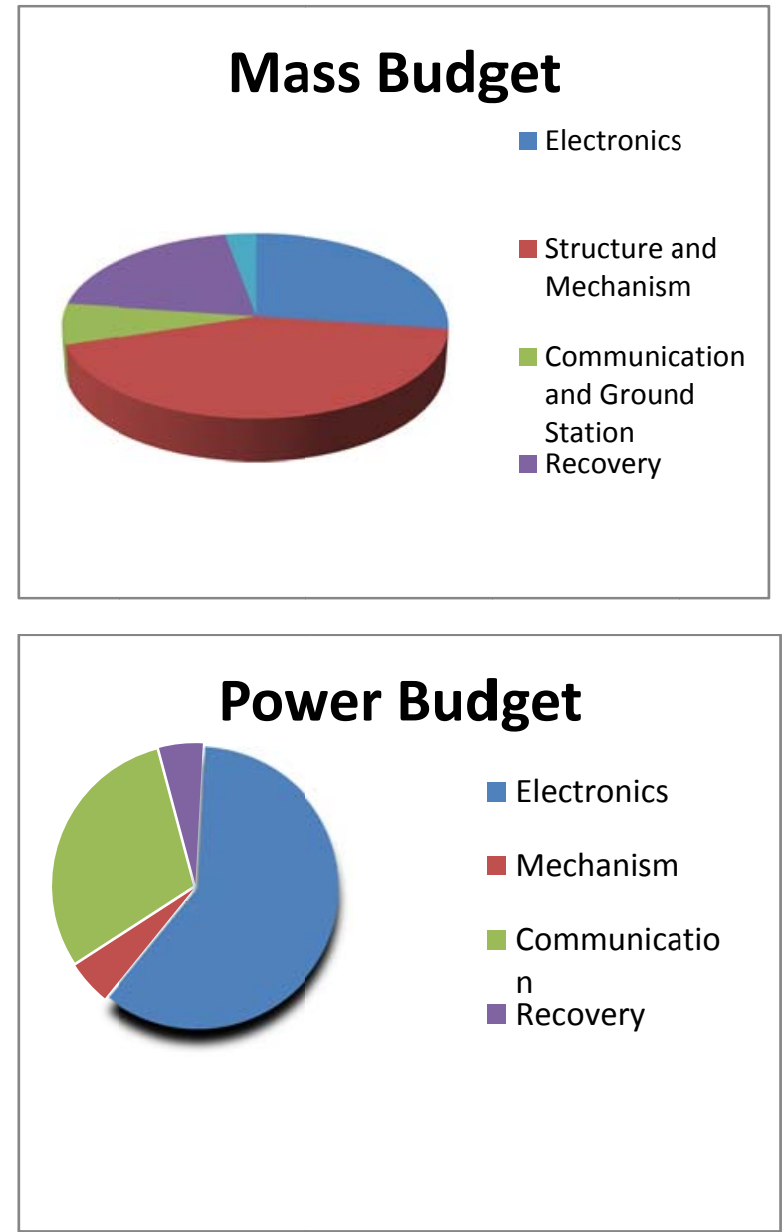

Fig. 6. Cost budget, Mass budget Volume budget and Power budget 


\subsection{Recovery Subsystem}

Parachute is a crucial element during the system mission. Its performance characteristics must be known and considered in calculating the descent rate. Based on recovery system requirements, the parachute was designed for these conditions:

- Maximum weight of parachute and payload: 350 gram

- Terminal velocity: $5 \mathrm{~m} / \mathrm{s}$

- Recovery altitude: $1000 \mathrm{~m}$

- Maximum shock: 10g

Achieving both desired descent rate and stable decent are key parameters in parachute design.

A parachute is a device used for slowing the motion of an object through an atmosphere by creating drag, or in the case of ram-air parachutes, aerodynamic lift. Parachutes are usually made out of light, strong cloth, originally silk, now most commonly nylon. Table 6 compares some type of parachute used for mission of cansat (Knacke (1991)).

Table 6. Compare of parachutes

\begin{tabular}{cccccccc}
\hline Type & Stability & Descent rate & Cost & Simplicity & Rate Of Climb & Drift & Maneuver \\
\hline Round & Low & High & Low & Middle & Low & High & Low \\
Cross & Middle & High & Low & High & Low & Middle & Low \\
Parafoil & High & High & High & Low & High & Low & High \\
\hline
\end{tabular}

The system is hanging up under a parafoil wing, which enables us to control the path of the module. The wing is tied to the system with two main lines. Two other thinner lines allow changing the direction (direction lines). The microcontroller sends orders for two servomotors. On each servomotor a wheel is fixed, on which direction lines are attached. It enables to pull or release the line. That permits to go straight, right, left and faster (by pulling both of the direction lines at the same time, because each line is independent). That allows us to have high maneuverability, to forecast and react to different atmospheric conditions (Watanabe and Ochi (2007, September)).

The shape of parafoil also heavily influences the flight performance, as well as opening characteristics. For selection of the parafoil for system, wing loading and canopy shape were considered for the driving factors in parafoil selection. After analyzing the possible airfoil for system parachute we choose Clark $\mathrm{Z}$ airfoil because it has maximum stall angle and maximum lift over drag and also design of this airfoil is not complex. According to Eq. (1) and parachute design the speed of system should be $5 \mathrm{~m} / \mathrm{s}$ (Zhao and Jianyi (2009, June)).

$$
r=\sqrt{\frac{2 F_{D r a g}}{\pi C_{d} \rho v^{2}}}
$$

$\rho=$ Air Density $=1.22 \mathrm{~kg} / \mathrm{m} 3 \quad \mathrm{v}=$ Velocity $(\mathrm{m} / \mathrm{s}) \quad \mathrm{F}=$ Drag Force $(\mathrm{N}) \quad \mathrm{r}=$ radius of Parachute (meter) $\mathrm{C}_{\mathrm{d}}=$ drag coefficient

The parachute was simulated and designed with foil maker software.

\subsection{Ground station}

The ground station consists of a laptop, an antenna and a receiver module. The receiver module collects the transmitted data and these data are plotted using MATLAB software. A sample data has been depicted in Fig. 7. After receiving data from the system, the data transported to computer via USB to Serial converter. Then by using MATLAB software, received data were analyzed, different 
data were extracted and sensor's parameters were plotted versus time. Fig. 7 shows the temperature, pressure, humidity, location and altitude parameters versus time.

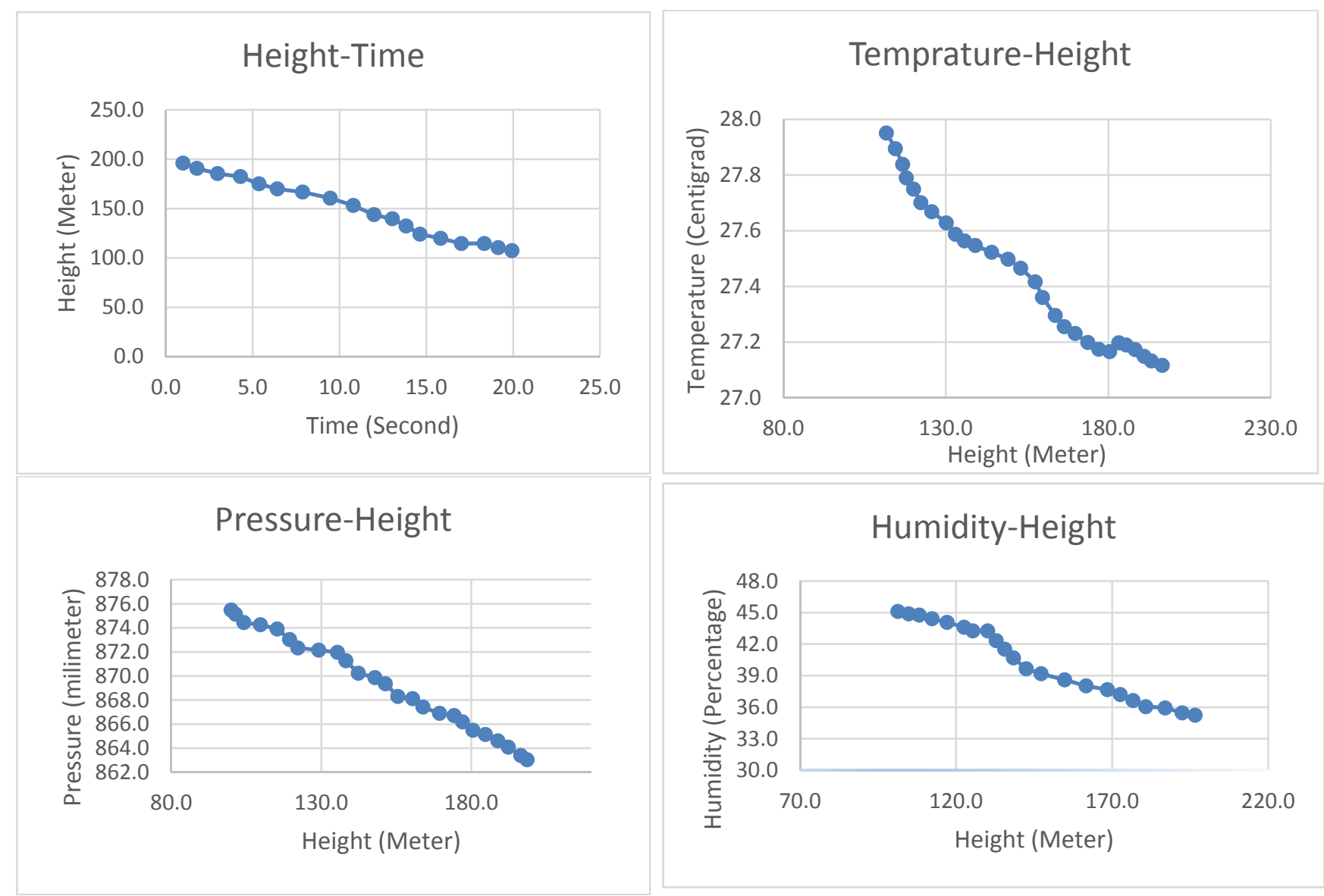

Fig.7. Height, Temperature, Pressure and Humidity Figures

\section{Conclusion}

In this research, we defined a systematic approach for designing and implementing a modified reusable atmospheric data acquisition flying vehicle system for online sight telemetry applications. This method could be considered as an effective method for design analysis of complicated systems. Using this way leads to visualize different parameters and their influences on the whole system and provides a better insight to the system levels hierarchy.

The main achievements of designing and implementing of the reusable atmospheric data acquisition system could be considered in two complementary viewpoints, technical and systematic achievements. Some of the most important technical achievements are experiences on design and fabrication of data handling subsystem, parachute, structures, mechanisms, on board programming, getting familiar with online transceiver modules. However, the most important systematic achievements are, team work, getting familiar with system design, getting familiar with different aspects of aerospace science, interaction with industry. 


\section{Acronyms}

\begin{tabular}{ll}
\hline Sat & Satellite \\
GPS & Global Position System \\
\hline UART & Universal asynchronous receiver/transmitter \\
\hline SPI & Serial Peripheral Interface \\
PIC & Peripheral Interface Controller \\
mA.h & Milli Ampere Hour \\
RF & Radio Frequency \\
I'C & serial to computer bus \\
MCU & Microcontroller \\
PCB & Printed circuit board \\
MEMS & Micro Electro Mechanical System \\
TX & Transmit unit \\
V & Voltage \\
G & Acceleration constant \\
\hline
\end{tabular}

\section{References}

Eerkens, M. R., Van Breukelen, E., Verhoeven, C., Vollebregt, M. S., \& Fitié, A. (2008, September). The Dutch CanSat competition: How 350 secondary school pupils compete to build the most innovative satellite in a soda can. International Astronautical Congress.

Ghorbanpanah, H., Moghaddam, M. H., Saeedi, A., \& Alishahi, S. (2013, January). Design and implementation of building energy monitoring system using wireless sensor networks. In Electricity Distribution (CIRED 2013), 22nd International Conference and Exhibition on (pp. 14). IET.

Knacke, T. W. (1991). Parachute recovery systems design manual (No. NWC-TP-6575). Naval Weapons Center China Lake, CA.

LaCombe, J. C., Wang, E. L., Nicolescu, M., Rivera, P., \& Poe, B. (2007, April). Design experiences with a student satellite program. In Proceedings of the 2007 American Society for Engineering Education Pacific Southwest Annual Conference.

Ley, W., Wittmann, K., \& Hallmann, W. (Eds.). (2009). Handbook of space technology (Vol. 22). John Wiley \& Sons.

Nylund, A., \& Antonsen, J. (2007). CANSAT-GENERAL INTRODUCTION AND EDUCATIONAL ADVANTAGES. In Proceedings of the 18th ESA Symposium on European Rocket and Balloon Programmes and Related Research, Visby.

PIC18FXX2 Data Sheet, H. P. (2006). Enhanced Flash Microcontrollers with 10-Bit A/D. Microchip

Technology Inc.

Wasson, C. S. (2006). System analysis, design, and development: Concepts, principles, and practices (Vol. 22). John Wiley \& Sons.

Watanabe, M., \& Ochi, Y. (2007, September). Modeling and motion analysis for a powered paraglider (PPG). In SICE, 2007 Annual Conference (pp. 3007-3012). IEEE.

Wertz, J. R., \& Larson, W. J. (1999). Space mission analysis and design, third Edition.

Zhao, L., \& Jianyi, K. (2009, June). Path Planning of Parafoil System Based on Particle Swarm Optimization. In Computational Intelligence and Natural Computing, 2009. CINC'09. International Conference on (Vol. 1, pp. 450-453). IEEE. 